\title{
RELATORIO DO ANNO DE 1917
}

N. ${ }^{\circ} 2$

Cumprindo o disposto na letra $i$ do artigo 114 do decreto n. 1I.530, de 18 de Março de 1915 e do n. XVII do artigo 9. ${ }^{\circ}$ do Regimento Interno desta Faculdade, passo a fazer o relatorio minucioso de tudo quanto occorreu neste estabelecimento a respeito da ordem, disciplina, observancia das leis e do orçamento, do anno lectivo findo de 1917

Abertura dos trabalhos. - Na fórma do artigo 74. do Decreto n. 11.530, de 18 de Março de 1915 e do artigo 143 do Regimento Interno desta Faculdade, os trabalhos deste instituto de ensino abriram-se no dia $1 . \circ$ de Março, celebrando a Congregação dos professores a sua primeira sessão.

Presença dos professores. - Na primeira reunião da Congregação do anno lectivo findo, realizada a $10^{: 0}$ de Março, ficou verificado que se achavam presentes e promptos para os cursos os professores Doutores: Uladislau Herculano de Freitas, Antonio Amancio Pereira de Carvalho. Antonio Januario Pinto Ferraz, Manoel Pedro Villaboim, José Ulpiano Pinto de Souza, Gabriel José Rodrigues de Rezende, Reynaldo Porchat, Dario Sebastião de Oliveira Ribeiro, João Braz de Oliveira Arruda, Luiz Barbosa da Gama Cerqueira, Estevam de Araujo Almeida, José Mendes, Manoel Pacheco Prates, José Manoel de A'zevedo Marques, Manoel Aureliano dé Gusmão, e os substitutos, na regeneia das cadeiras: Frederico Vergueiro Steidel e Raphael Corrêa Sampaio, alem do Doutor Ernesto Moura. 
que continúa em disponibilidade, e dos substitutos, que não regiam cadeiras, Doutores: José de Alcantara Machado d'Oliveira, Theophilo Benedicto de Souza Carvalho e José Augusto Cesar.

Exame vestibular. - Na fórma do artigo 62 do Regimento Interno desta Faculdade, a inscripção para o exame vestibular, instituido pelo artigo 77, letra $c$, do decreto n. 11.530, de 18 de Março de 1915, para a matricula no curso desta Faculdade, aberta a 2 de Janeiro e prorogada, de conformidade com o telegramma do Exmo. Snr. Dr. Ministro da Justiça e Negocios Interiores, de 27 de Dezembro de 1916, foi encerrada a 3 de Fevereiro, tendo a ella concorrido trinta e sete (37) candidatos. O exame começou com a prova escripta no dia 31 de Janeiro e terminou a 28 de Março, em consequencia de ter a inscripção de uma turma de candidatos ficado dependente da resolução do "Conselho Superior do Ensino. O resultado do julgamento desse exame consta do annexo sob n. II, e foi o seguinte: Approvados 12, inhabilitados na prova escripta 20 e reprovados 5. A commissão julgadora do exame vestibular foi constituida na sessão da Congregação dos professores, realizada á 8 de Janeiro, dos professores-Doutores: Frederico Vergueiro Steidel, João Braz de Oliveira Arruda, Estevam de Araujo Almeida, José Mendes, Manoel Aureliano de Gusmão e José Augusto Cesar.

Horario das aulas. - Pela Congregação dos professores, em sessão de $1 .^{\circ}$ de Março, foi adoptado o horario constante do respectivo quadro.

Programmas de ensino. - Adoptados pelos profesres das cadeiras do curso, foi nomeada uma commissão composta dos Doutores: Manoel Pedro Villaboim, João Braz de Oliveira Arruda e Estevam de Araujo Almeida, que formularam o seu parecer, que foi approvado na ses- 
são de 16 de Março. Os programmas foram impressos e postos á venda na Thesouraria da Faculdade.

Designação de professores. - Durante o anno, foram designados os professores Doutores: Estevam de Araujo Almeida, professor cathedratico, para reger a $3 .^{\mathrm{a}}$ cadeira do $1 .^{\circ}$ anno, em substituição ao Doutor Reynaldo Porchat; Manoel Pacheco Prates, professor cathedratico, para reger a $4 .^{a}$ cadeira do $5 .^{\circ}$ anno, em substituição ao Doutor Manoel Pedro Villaboim; Frederico Vergueiro Steidel, professor substituto da $6 .^{\prime}$ secção, para reger a $1 .^{n}$ cadeira do $4 .^{\circ}$ anno, em substituição ao Doutor Brazilio Augusto Machado d'Oliveira, e a $1 .^{a}$ cadeira do 3 . anno, em substituição ao Doutor Gabriel José Rodrigues de Rezende; Raphael Corrêa de Sampaio, professor substituto da $4 .^{a}$ secção, para reger a 2." cadeira do $3 .^{\circ}$ anno, em substituição ao Doutor Candido Nazianzeno Nogueira da Motta, e a 2." cadeira do $4 .^{\circ}$ anno, em substituição ao Doutor Luiz Barbosa da Gama Cerqueira; Manoel Aureliano de Gusmão, professor substituto da $7 .^{a}$ secção, para reger a $1 .^{a}$ cadeira do $5 .^{\circ}$ anno, vaga pela nomeação do Doutor João Mendes de Almeida Junior, para o cargo de Ministro do Supremo Tribunal Federal; José Augusto Cesar, professor substituto da $3 .^{a}$ secção para reger a $3 .^{a}$ cadeira do $3 .^{\circ}$ anno, em substituição ao Doutor José Ulpiano Pinto de Souza; e Theophilo de Souza Carvalho, professor substituto da 2." secção para reger a $2 .^{a}$ cadeira do $2 .^{\circ}$ anno, em substituição ao Doutor Dario Sebastiấo de Oliveira Riheiro, e a l. ${ }^{a}$ cadeira do $1 .{ }^{\circ}$ anno, em substituição ao Doutor Uladislau Herculano de Freitas.

Verificação da inscripção de exames da segunda epoca. - Para os exames da segunda epoca inscreveram-se 100 alumnos, sendo: no $1 .^{\circ}$ anno 8 , no $2 .^{\circ}$ anno 34 , no $3 .^{\circ}$ anno 25, no 4 . anno 22 e no $5 .^{\circ}$ anno 11 . 
Resultado desses exames. - 0 resultado desses exames consta do respectivo quadro.

Da inscripção de matrịcula. - Matricularam-se nos cinco annos de curso 437 alumnos, sendo: no $1 .^{\circ}$ anno 35 , no $2 .^{\circ}$ anno 69 , no $3 .^{\circ}$ anno 182 , no $4 .^{\circ}$ anno 81 e no 5 . anno 70 .

Das aulas. - As aulas foram abertas, na fórma do artigo 73 do Decreto n. 11.530, de 18 de Março de 1915 e do artigo 100 do Regimento Interno desta Faculdade, no dia 2 de Abril, por ter sido domingo o dia $1 .{ }^{\circ}$, e funccionaram com a maxima regularidade até ao dia 14 de Novembro, em que foram encerradas, por ter sido feriado o dia 15 , tendo apenas sido interrompidas com as ferias da segunda quinzena de Junho.

Transferencia de matricula. - Durante o anno, apenas quatro alumnos requereram guia de transferencia, serdo do 1. anno para a Faculdade Livre de Direito do Rio de Janeiro, 1 do $2 .^{\circ}$ anno para a Faculdade Livre de Sciencias Juridicas e Sociaes do Rio de Janeiro e 1 do $4 .^{\circ}$ anno para a Faculdade de Direito do Recife.

Exames parciaes. - Na fórma do artigo 103 do Decreto n. 11.530, de 1915, já citado, e do artigo 102 do Regimento Interno desta Faculdade, tambem já referido, na primeira quinzena de Junho e na segunda de Agosto. se realizaram os exames parciaes, a que se submetteram os alumnos dos cincos annos do curso, sendo de notar que apenas muito poucos deixaram de a elles comparecer.

Licenças. - Durante o anno, estiveram em gozo de licença os professores cathedraticos, Doutores: José Ulpiano Pinto de Souza, de 10 de Setembro a 9 de Outubro; Gabriel José Rodrigues de Rezende, de 8 de Outubro a 7 de Novembro; Reynaldo Porchat, de 16 de Agosto a 15 de Outubro; Dario Sebastião de Oliveira Ribeiro, de 12 
de Abril a 11 de Dezembro e Luiz Barbosa da Gama Cerqueira, de 1 a 15 de Agosto.

Substituições. - No correr do anno lectivo, o Dr. Antonio Amancio Pereira de Carvalho, professor cathedratico mais antigo e vice-Director, na fórma da lei, substituiu ao Dr. Uladislau Herculano de Freitas, no exercicio do cargo de Director de 1 a 22 de Fevereiro, e de 16 Julho a 6 de Agosto; o Dr. Estevam de Araujo Almeida, professor cathedratico, substituiu ao Dr. Reynaldo Porchat, na regencia da $3 .^{\mathrm{a}}$ cadeira do $1 .^{\circ}$ anno, de 16 de Julho a 15 de Outubro; o Dr. Manoel Pacheco Prates, professor cathedratico, substituiu ao Dr. Manoel Pedro Villaboim, na regencia da $4 .^{a}$ cadeira do $5 .^{\circ}$ anno, de 4 de Maio a 31 de Dezembro; o Dr. Frederico Vergueiro Steidel, professor substituto da 6 . $^{a}$ secção, substituiu ao Dr. Brazilio Augusto Machado d'Oliveira, na regencia da 1. ${ }^{a}$ cadeira do $4 .^{\circ}$ anno, de 1 de Janeiro a 31 de Dezembro, e ao Dr. Gabriel José Rodrigues de Rezende, na regencia da $1 .^{a}$ cadeira do $3 .^{\circ}$ anno, de 8 de Outubro a 7 de Novembro; o Dr. Raphael Corrêa de Sampaio, professor substituto da $4{ }^{\text {a }}$ secção, substituiu ao Dr. Candido Nazianzeno Nogueira da Motta, na regencia da $2 .^{a}$ cadeira do $3 .^{\circ}$ anno, de $1 .^{\circ}$ de Janeiro a 31 de Dezembro e ao Dr. Luiz Barbosa da Gama Cerqueira, na regencia da $2 .^{a}$ cadeira do $4 .^{\circ}$ anno, de 1 a 15 de Agosto; o Dr. José Augusto Cesar, professor substituto da $3 .^{a}$ secção, substituiu ao Dr. José Ülpiano Pinto de Souza, na regencia da 3. ${ }^{a}$ cadeira do 3." anno, de 10 de Setembro a 9 de Outubro; o Dr. Theophilo Benedicto de Souza Carvalho, professor substituto da 2 . $^{a}$ seç̧ão, substituiu ao Dr. Uladislau Herculano de Freitas, na regencia da $2 .^{a}$ cadeira do $1 .^{\circ}$ anno, de 16 de Julho a 6 de Agosto, e ao Dr. Dario Sebastião de Oliveira Ribeiro, na regencia da $2 .^{\text {a }}$ cadeira do $2 .^{\circ}$ anno, de 12 de Abril a 11 de Dezembro; e o Dr. Manoel Aureliano de Gusmão, pro- 
fessor substituto da 7 . $^{\mathrm{a}}$ secção, substituiu ao Dr. João Mendes de Almeida Junior, na regencia da 1. " cadeira da do 5." anno, de 8 a 21 de Janeiro.

Serviço publico. - Durante o anno findo, estiveram ausentes desta Faculdade, por motivo de serviço publico: o Dr. Uladislau Herculano de Freitas, no exercicio do cargo de Director e como representante desta Faculdade, no Conselho Superior do Ensino, de 1 a 22 de Fevereiro e a 16 de Julho a 6 de Agosto; o Dr. Brazilio Augusto Machado d'Oliveira, como presidente do Conselho Superior .do Ensino, de 1. ${ }^{\circ}$ de Janeiro a 31 de Dezembro; o Dr. Reynaldo Porchat, como representante desta Faculdade. no Conselho Superior do Ensino, de 1 a 20 de Fevereiro e de 16 de Julho a 10 de A'gosto; o Dr. Manoel Pedro Villaboim, com assento no Congresso Nacional, como Deputado por este Estado de São Paulo, de 3 de Maio a 31 de Dezembro; o Dr. Candido Nazianzeno Nogueira da Motta, como Secretario da Agricultura deste Estado de São Paulo, de $1 .^{\circ}$ de Janeiro a 31 de Dezembro, e o Bacharel Luiz de Andrade Vasconcellos Junior, Bibliothecario, em serviço do Jury, de I a 31 de Agosto.

Sub-Secretario. - O Bacharel Aureliano Amaral, do dia 7 de Maio, em diante, passou a ter exercicio na Secretaria do Conselho Superior do Ensino, como requereu e conforme foi declarado pelo Aviso n. 319 de 7 de Abril. do Ministerio da Justiça e Negocios Interiores.

Vaga da $1 .^{\text {a }}$ cadeira do 5. anno. - Com a posse, no dia 5 de Janeiro, do Dr. João Mendes de Almeida Junior, professor cathedratico, no cargo de Ministro do Supremo Tribunal Federal, para qual foi nomeado por Decreto de 11 de Dezembro de 1916, ficou vaga a $1 .^{a}$ cadeira do $5 .^{\circ}$ anno (Theoria e Pratica do Processo Civil e Commercial).

Nomeação e posse de professor cathedratico. - Por Decreto de 10 de Janeiro o Dr. Manoel Aureliano de Gus- 
mão, professor substituto da $7 .^{a}$ secção, foi nomeado professor cathedratico da cadeira de Theoria e Pratica do Processo Civil e Commercial (1. ${ }^{\mathrm{a}}$ cadeira do 5. anno), vaga pela nomeação do Dr. João Mendes de Almeida Junior para o cargo de Ministro do Supremo Tribunal Federal, tendo iomado posse e entrado em exercicio do cargo no dia 22 do mesmo mez.

Vaga de logar de professor substituto. - Com a posse do Dr. Manoel Aureliano de Gusmão, professor substituto da $7 .:$ secção, no logar de professor cathedratico da $1 .{ }^{a}$ cadeira do $5 .^{\circ}$ anno, verificou-se a vaga do logar de professor substituto da $7^{\text {a }}$ secção.

Inscripção para os concursos de professores substitutos. - De conformidade com o disposto no arts. 43, 44 e 45 do Decreto n. 11.530, de 18 de Março de 1915 e dos arts. 44, e 45 do Regimento Interno desta Faculdade, foi no dia 18 de Abril, aberta na Secretaria a inscripção, pelo prazo de cento e vinte dias, para o preenchimento dos logares vagos de professores substitutos das primeiras, quinta e setima secções, comprehendendo a primeira secção as materias seguintes: Philosophia do Direito e Direito Romano; a quinta Economia Politica e Sciencia das Finanças e Direito Administrativo; e a setima Theoria do Processo Civil e Commercial e Pratica do Processo Civil e Commercial, conforme edital que foi regularmente publicado, encerrando-se a mesma no dia 16 de Agosto, ás 13 horas, sendo lavrados os respectivos termos de abertura e encerramento. Dentro do prazo, inscreveram-se: na $1 .^{a}$ secção, os Bachareis Laurentino Antonio Moreira de Azevedo, no dia 31 de Maio; Spencer Vampré, no dia 6 de Julho e Alexandre Corrêa, no dia 31 de Julho; na $5 .^{\mathrm{a}}$ secção, os Bachareis José Joaquim Cardoso de Mello Neto, no dia 19 de Abril; Braz de Sousa Arruda, no dia 21 de Maio; Arnaldo Porchat, no dia 14 de Agosto, e Gastão 
Netto dos Reys, no dia 16 de Agosto, e na $7^{\text {a }}$ seç̧ão, os Bachareis Francisco Antonio de Almeida Morato, no dia 1. ${ }^{\circ}$ de Maio; Gabriel José Rodrigues de Rezende Filho, no dia 13 de Agosto, e Octavio Vianna Martins, no dia 16 de Agosto.

Commissóes julgadoras nos concursos para o preenchimento dos logares de professores substitutos, dals 1. ${ }^{\mathrm{a}}, 5^{\mathrm{a}}$ e 7. ${ }^{\text {a }}$ secções. - Nas sessões da Congregação dos professores, realizada nos dias 22 de Agosto e 10 de Setembro, de conformidade com o disposto na letra $b$, do art. 45 do Regimento Interno desta Faculdade, e da letra $i$, do art. 70 do. Decreto n. 11.530, de 18 de Março de 1915, foram contituidas as commissões julgadoras nos concursos para o preenchimento dos logares vagos de professores substitutos, na fórma seguinte: para a da $1 .^{2}$ secção, dos professores Drs. José Augusto Cesar, Manoel Pacheco Prates, José Mendes e Estevam de Araujo Almeida; para a da 5. secção, dos Drs. Theophilo Benedicto de Souza Carvalho, Raphael Corrêa de Sampaio, Manoel Pacheco Prates e José Mendes; e para a da 7. ${ }^{a}$ secção, dos Drs. José Augusto Cesar, Manoel Aureliano de Gusmão, José Manoel de Azevedo Marques e Estevam de Araujo Almeida.

Provas dos concursos. - - De conformidade com a resolução da Congregação dos professores, tomada em sessão realizada a 22 de Agosto, no dia 17 de Setembro, teve inicio a primeira prova do concurso para o preenchimento do logar vago de professor substituto da $5 .^{a}{ }^{a}$ secção, que comprehende: Economia Politica e Sciencia das Finanças e Direito Administrativo, realizando-se as demais provas nos dias $18,19,20,21,22,25$ e 26 do mesmo mez, effectuando-se o julgamento no mesmo dia 26 , após a arguição do ultimo candidato, tendo sido, nesse julgamento, e, em primeiro escrutinio, approvados, por unanimidade de votos os quatro candidatos inscriptos: Bachareis José Joa- 
quim Cardoso de Mello Neto, Braz de Souza Arruda, Arnaldo Porchat e Gastão Netto dos Reys, e, sendo, no segundo escrutinio, lassificado em primeiro logar, por sete votos, o Bacharel José Joaquim Cardoso de Mello Neto, que foi indicado ao Governo para ser nomeado.

As provas do concurso para preenchimento do logar vago de professor substituto da $1 .^{a}$ secção, que comprehende: Philosophia do Direito e Direito Romano, se realizaram nos dias 27 e 28 de Setembro, 1. 2 e 4 de Outubro, ef. fectuando-se o julgamento no mesmo dia 4, após a arguição do ultimo candidato, tendo sido, nesse julgamento e, em primeiro escrutinio, approvados, por unanimidade de votos, os tres candidatos inscriptos, Bachareis Laurentino Antonio Moreira de Azevedo, Spencer Vampré e Alexandre Corrêa, e sendo, em segundo escrutinio, classificado em primeiro logar, por sete votos, o Bacharel Spencer Vampré, que foi indicado ao Governo, para ser nomeado.

As provas do concurso para preenchimento do logar vago de professores substituto da setima secção, que comprehende: Theoria do Processo Civil e Commercial e Pratica do Processo Civil e Commercial, se realizaram nos dias $8,9,10,16$ e 17 de Outubro, effectuando-se o julgamento no mesmo dia 17 , após a arguição do ultimo candidato, tendo sido, nesse julgamento e, em primero escrutinio, approvados, por unanimidade de votos, os tres candidatos inscriptos, Bachareis Francisco Antonio de Almeida Morato, Gabriel José Rodrigues de Rezende Filho e Octavio Vianna Martins, e, sendo, em segundo escrutinio, classificado em primeiro logar, por nove votos, o Bacharel Francisco Antonio de Almeida Morato, que foi indicado ao Governo, para ser nomeado.

Recurso. - O Bacharel Braz de Sousa Arruda, candidato inscripto no concurso para o preenchimento do logar de professór substituto da quinta secção, em data 
de 29. de Setembro, recorreu ao Ministro da Justiça e Negocios Interiores do acto da Congregação dos professores desta Faculdade, classificando em primeiro logar o Bacharel José Joaquim Cardoso de Mello Neto no concurso da referida quinta secção. Por acto do Ministro da Justiça e Negocios Interiores, de 11 de Outubro, foi negado provimento a esse recurso, sendo confirmado o acto da mesma Congregação.

Nomeações e posses de professores substitutos. - $\mathrm{O}$ Bacharel José Joaquim Cardoso de Mello Neto, nomeado professor substituto da quinta seçãa, por Decreto de 11 de Outubro, tomou posse e entrou no exercicio do cargo no dia 18 do mesmo mez; o Bacharel Spencer Vampré, nomeado professor substituto da primeira secção, por Decreto de 17 de Outubro, tomou posse e entrou no exercicio do cargo, no dia 31 do mesmo mez, e, o Bacharel Francisco Antonio de Almeida Morato, nomeado professor substituto da setima secção, por Decreto de 31 de Outubro, tomou posse e entrou no exercicio do cargo, no dia 13 de Novembro.

Representante da Congregação no Conselho Superior do Ensino. - Em sessão especial da Congregação dos professores, realizada a 16 de Abril, foi o Dr. Reynaldo Porchat, professor Cathedratico, eleito, por unanimidade de votos, representante da mesma Congregação junto ao Conselho Superior do Ensino, para o biennio de 19171918.

Alterações feitas no Regimento Interno. - Em sessão da Congregação, realizada a 11 de Junho, foram approvadas pela mesma Congregaçãa as alterações feitas nos arts: 14, 45, 129, 133, 135, 137, 202 e 205, de accordo com a proposta da commissão anteriormente nomeada e composta dos professores Drs. Reynaldo Porchat, Estevam de Araujo Almeida e Frederico Vergueiro Steidel. 
A commissão propoz e a Congregação approvou, na mesma sessão, que a taxa para a inscripção de exame de estudantes não matriculados fosse elevada a Rs. $250 \$ 000$ (duzentos e cincoenta mil réis) Essas propostas foram submettidas á decisão do Conselho Superior do Ensino, que as approvou, em sessão de 21 de Julho, com a proposta apresentadas pelos Drs. Herculano de Freitas, Araujo Lima e Ortiz Monteiro, relativa á taxa de cartas de Doutor e Bacharel, de accordo com a proposta do Dr. Herculano de Freitas, approvada em sessão do Conselho Superior do Ensino de 27 de Fevereiro, sendo, portanto, as alterações feitas no Regimento Interno, as seguintes:

Art. 14. A Congregação será convocada e presidida pelo Director, guardando-se a ordem de precedencia dentre os professores pela antiguidade de sua posse, respeitada a graduação hierarchica, e deliberará, segundo as normas deste Regimento.

Art. 45. O concurso para professores substitutos e para livre docente comprehenderá:

a) Um trabalho do valor sobre cada uma das materias da secção, sendo o assumpto escolhido, dentre os que forem indicados pela Congregação para as defesas de theses ou uma obra systematica sobre cada uma das materias da secção; producções que deverão ser impressas, entregando o candidato, no dia do encerramento da inscripção, 50 exemplares ao Secretario, que passará recibo e fará distribuir pelos membros da Congregação;

b) Arguição do candidato pèla mesa examinadora, composta de quatro professores, durando cada arguição o maximo de meia hora. A mesa examinadora será formada dos cathedraticos da secção, e se completará com outros professores eleitos, de accordo com o art. 70, letra $i$, do Decreto n. 11.530; e, assim constituida, terá a sua competencia firmada para todo o processo do concurso. 
Art. $50 \oint 2 . \quad$ No caso de empate, o Director terá o voto do desempate, além do voto que houver dado como professor effectivo, quando fôr;

Art. 129. As notas dadas pelo professor da cadeira, em exercicio, serão: Má, Soffrivel, Regular, Bôa, e terão para os calculos dos pontos o mesmo valor dos exames parciaes;

Art. 133. A prova oral consistirá em exposição ou arguição, que terá por objecto um dos pontos da materia explicada em cada cadeira, sorteado no momento, em um maximo de quinze minutos, iniciada a arguição pelo professor de nomeação mais recente; não sendo licito arguir sobre ponto differente, mas podendo tambem interrogar o alumno sobre todas as provas escriptas ou qualquer dellas, assim dos exames parciaes como dos finaes;

Art. 135. O julgamento se fará da seguinte fórma: Sommadas as notas de todas as provas, inclusivé a oral, que terá o mesmo valor das outras, ajuntado o valor da frequencia, si o alumno a elle tiver direito (art. 91), e o das bôas licçóes, si a mesa acceitar a proposta do professor nesse sentido (art. 136), e, feita a deducção do máu exame oral, si fôr caso disso; si o resultado fôr de 12 a 24, o alumno estará approvado simplesmente; de 27 a 33, plenamente, e de 36 a 39 , com distinção; si não attingir a 12 , estará reprovado;

Art. 137. O exame oral não importará obrigatoriamente, para o alumno, na diminuição de 10 pontos na somma dos valores;

Art. 207 O gráu será conferido por um dos examinadores da mesa do quinto anno, revezando-se uns aos outros pela ordem de antiguidade, e a ceremonia terá lugar no salão nobre da Faculdade; 
Art. 245. Em hypothese alguma, sahirão da Bibliotheca livros, folhetos, impressos ou manuscriptos, salvo quando fornecidos a professores, mediante recibo, pelo prazo maximo de quinze dias.

\section{TABELLA}

Taxa de carta de Doutor em Sciencias, Juridicas e Sociaes $200 \$ 000$;

Taxa de carta de Bacharel em Sciencias Juridicas e Sociaes $100 \$ 000$;

Taxa de inscripção de exame para estudante não matriculado $250 \$ 000$.

Professor Honorario. - Por indicação do professor Dr. João Braz de Oliveira Arruda, unanimamente e sem discussão, approvada em sessão da Congregação dos professores, realizada a 31 de Outubro, e, de accordo com o disposto no art. 53, do Decreto n. 11.530, de 18 de Março de 1915 e do art. 42 do Regimento Interno desta Faculdade, foi eleito professor honorario desta Faculdade o Conselheiro Dr. Ruy Barbosa, que, em data de 9 de Novembro agradeceu a Congregação o honroso titulo, que esta lhe conferira.

Premios. - No anno findo, por deliberação da Congregação, foram pagos aos Bachareis Lourenço de Freitas Camargo, Braz de Souza Arruda e Orlando Fonseca, que maior numero de notas distinctas obtiveram, aquelle, 8 de distinç̧ões e 6 plenamente, no quinquennio de 1911 a 1915, e estes, 16 distinç̧ões, cada um, no quinquennio de 1912 a 1916, os juros das apolices que constituem o "Premio Rodrigues Alves", e aos Bachareis Braz de Souza Arruda e Orlando Fonseca, que maior numero de notas distinctas obtiveram, cada um, 16 distincções, no quinquennio de 
1912 a 1916, os juros das apolices que constituem o "Premio Duarte de Azevedo"

Acquisição de Apolices Federaes. - Pelo Director Dr. Uladislau Herculano de Freitas, mediante autorização da Congregação dos professores, tomada em sessão de 8 de Janeiro e approvada pelo Conselho Superior do Ensino, em sessão de 27 de Fevereiro, foram adquiridas trezentos e nove (309) apolices da divida publica nacional, do valor de um conto de réis (1:000\$), cada uma, para a constituição do patrimonio desta Faculdade.

Inscripções para os exames da primeira epoca. Para estes exames se inscreveram 379 alumnos, sendo: 22 no $1 .^{\circ}$ anno, 57 no $2 .^{\circ}, 158$ no $3 .^{\circ}, 76$ no $4 .^{\circ}$ e 66 no $5 .^{\circ}$.

Resultado desses exames. - 0 resultado desses exames consta do respectivo quadro.

Collação de grau. - Durante o anno, foi collado o grau de Doutor em Sciencias Juridicas e Sociaes a tres Bachareis em Sciencias Juridicas e Sociaes, ex-vi do disposto nos arts. 43 e 211 do Regimento Interno desta Faculdade, por terem sido nomeados professores substitutos das

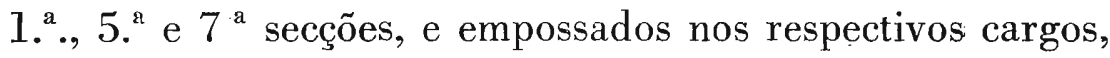
sendo os tres naturaes deste Estado, e o de Bacharel em Sciencias Juridicas e Sociaes a 79 Bacharelandos, dos quaes dois concluiram o seu curso em 1914 e 77 o concluiram no anno findo, sendo 11 na segunda epoca e 66 na primeira. Desses 79 Bachareis, 55 são naturaes do Estado de S. Paulo, 9 do de Minas Geraes, 3 do de Pernambuco, 2 do da Bahia, 2 do do Paraná, 1 do do Rio Grande do Sul, 1 do do Ceará, 1 do da Parahyba, 1 da Cidade do Rio de Janeiro, 1 de Portugal, e 1 da Syria, conforme se vê do respectivo quadro.

Cartas de Doutor e Bacharel. - Durante o anno, foram expedidas 259 cartas, sendo 1 de Doutor, a um bacha- 
relando em Sciencias Juridicas e Sociaes, formado por esta Faculdade, e habilitado em concurso, em 1897, e que é natural do Estado do Paraná, e 258 de Bacharel a egual numero de Bachareis, formados por esta Faculdade, dos quaes 5 formados em Sciencias Juridicas somente, e 253 formados em Sciencias Juridicas e Sociaes. Desses 258 Bachareis, 180 são naturaes do Estado de São Paulo, 31 do de Minas Geraes, 19 do do Rio de Janeiro, 4 do da Bahia, 4 do de Sergipe, 3 do do Rio Grande do Sul, 2 do do Paraná, 2 do do Ceará, 2 do das Alagôas, 1 do de Santa Catharina, 1 do de Matto Grosso, 1 do de Goyaz, 1 do do Esprito Santo, 1 do de Pernambuco, 2 da Italia, 2 de Portugal, 1 da Hespanha e 1 do Chile, conforme se vê do respectivo quadro.

Procedimento dos alumnos. - $\mathrm{O}$ procedimento dos alumnos, no anno lectivo findo, foi bom, nada tendo occorrido digno de menção.

Sessões da Congregação. - No correr do anno findo, a Congregação dos professores celebrou 16 sessões, nas quaes foram tratados diversos assumptos.

Encerramento dos trabalhos. - Tendo terminado no dia 18 de Dezembro os exames do 4. anno, foram, no dia 27 desse mez, encerrados os trabalhos desta Faculdade.

Bibliotheca. - A Bibliotheca desta Faculdade foi frequentada, durante o anno lectivo findo, por 5.501 pessôas, que consultaram 1.815 obras, em 3.382 volumes, sendo em portuguez 1.387, em francez 298, em italiano 95, em latim 28, em hespanhol 4, em inglez 2 , em allemão 1 , estando no numero de consultantes incluidas 2.834 pessôas, que leram jornaes e revistas, como consta do respectivo quadro.

No correr do anno, entraram para a Bibliotheca 219 obras, sendo por compra 11, em 86 volumes, e 208, por 
doação, em 702 volumes, tendo sido encadernadas 20 obras em 92 volumes, e reencadernadas 60 , em 125 volumes, conforme o respectivo quadro. Os empregados da Bibliotheca bem cumpriram os seus deveres.

Thesouraria. - $\mathrm{O}$ balanço demonstrativo, fechado pelo Thesoureiro, em 31 de Dezembro, accusa que, da receita e despeza desta Faculdade, ha um saldo de quatrocentos e onze contos seiscentos e noventa e seis mil novecentos e noventa e quatro réis (411:696\$994), assim discriminados: Trezentas e nove apolices federaes do valor de um conto de réis (Rs. 1:000\$000), cada uma trezentos e nove contos de réis $(309: 000 \$ 000)$; no Banco de São Paulo, cinco contos duzentos e tres mil seiscentos e trinta e tres réis $(5: 203 \$ 633)$; no Banco de Commercio e Industria de São Paulo, quarenta e tres contos trezentos e seis mil réis $(43: 306 \$ 000)$; na Agencia do Banco do Brazil', trinta e tres contos de réis (33:000\$000); no Banco de Credito Hypothecario e Agricola, quinhentos e cincoenta e quatro mil e quatrocentos réis $(554 \$ 400)$, no London and Brasilian Bank, vinte contos duzentos e trinta e cinco mil e novecentos réis $(20: 235 \$ 900)$; e, em caixa, trezentos e noventa sete mil e sessenta e um réis (397\$061). O saldo apurado em 1916 foi de trezentos e dois contos trezentos e setenta e um mil novecentos e trinta e tres réis (302:371\$933), havendo, portanto, um excesso de cento e dezenove contos trezentos e vinte e cinco mil e sessenta e um réis (119:325\$061).

O Thesoureiro bem cumpriu os seus deveres.

Secretaria. - Os serviços da Secretaria estiveram sempre em dia, tendo os empregados bem cumprido os seus deveres.

Secretaria da Faculdade de Direito de São Paulo, em 22 de Janeiro de 1918.

O Director:

Dr. U. Herculano de Freitas 